\title{
Proteger la "democracia" desde el cuartel: la Doctrina de Estabilidad Nacional de los militares guatemaltecos*
}

\author{
Protecting "Democracy" \\ from the Barracks: The National Stability \\ Doctrine of Guatemalan Military Officers
}

\author{
Laura Yanina Sala** \\ (D) https://orcid.org/0000-0003-2463-0931 \\ Consejo Nacional de Investigaciones Científicas y Técnicas/ \\ Universidad de Buenos Aires/Universidad Nacional de José C. Paz, Argentina \\ laurasala@hotmail.com.ar
}

Resumen: Este artículo analiza la Doctrina de Estabilidad Nacional elaborada por el sector estratégico del Ejército de Guatemala. Aborda el proceso de su

* Este texto es una reescritura de la primera parte del tercer capítulo de mi tesis de maestría en Estudios Latinoamericanos por la Universidad Nacional de General San Martín (UNSAM) titulada La encrucijada militar: cambios políticos y fuerzas armadas en Guatemala, 1982-1996. Una aproximación sociohistórica a las transformaciones en la institución militar guatemalteca.

** Socióloga y doctoranda en Ciencias Sociales por la Universidad de Buenos Aires (UBA), maestra en Estudios Latinoamericanos por la UnSAM. Es becaria doctoral del Consejo Nacional de Investigaciones Científicas y Técnicas (CONICET) con sede en el Instituto de Estudios de América Latina y El Caribe (IEALC) por la UBA. Es docente regular de la Universidad Nacional de José C. Paz. Integra el Grupo de Estudios sobre Centroamérica (IEALC-UBA) (en http://geca.sociales. uba.ar/). Trabaja con herramientas de la Sociología Histórica, la Antropología y la Sociología Política. Sus temas abordan los procesos de violencia política en Centroamérica, las relaciones

cómo citar: Sala, L. Y. (2020). Proteger la "democracia” desde el cuartel: la Doctrina de Estabilidad Nacional de los militares guatemaltecos. Secuencia (107), e1705. DoI: https://doi.org/10.18234/secuencia. v0i107.1705 
elaboración a partir de indagar en los elementos de los debates políticos de la época que incorpora y reformula; y muestra cuáles son los planteamientos más importantes, y las transformaciones que introduce en el pensamiento militar. Plantea que la Estabilidad Nacional implica una nueva significación, conservadora y autoritaria, del conflicto social, de la democracia y de la función militar en la sociedad que guía las transformaciones en la institución armada y que se resume en la idea: "proteger la 'democracia' desde el cuartel". El artículo aporta al estudio de los cambios en la mentalidad de las fuerzas armadas y, a través de ello, al proceso de "transición autoritaria a la democracia" en Guatemala.

Palabras clave: fuerzas armadas; Doctrina de Estabilidad Nacional; pensamiento militar; democracia; subversión.

Abstract: This article analyzes the National Stability Doctrine designed by the strategic sector of the Guatemalan Army. It explores the process of its design by exploring the elements of the political debates of the time that it incorporated and reformulated, and shows the most important proposals and transformations it introduced into military thought. It posits that the national army implied a new, conservative and authoritarian signification of social conflict, democracy and military function in society that guided the transformations in the armed institution and can be summarized by the idea of "protecting 'democracy' from the barracks". The article contributes to the study of changes in the mentality of the armed forces and, through it, to the process of "authoritarian transition to democracy" in Guatemala.

Keywords: armed forces; National Stability Doctrine; military thought; democracy; subversion.

Recibido: 17 de enero de 2019 Aceptado: 20 de mayo de 2019

Publicado: 2 de marzo de 2020

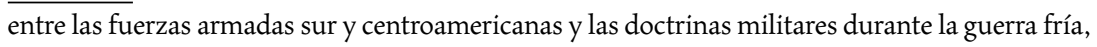
así como la guerra fría y los procesos transnacionales en ese periodo en América Latina. 


\section{INTRODUCCIÓN}

Como actores de este proceso de democratización, estamos convencidos que para preservar la democracia es necesario protegerla. Allí radica la importancia de las Fuerzas Armadas como garantes de la supervivencia del Estado.

General Héctor Alejandro Gramajo Morales ${ }^{1}$

T as fuerzas armadas guatemaltecas fueron quienes impulsaron -en los Laños ochenta- la transición de un régimen dictatorial a una institucionalidad democrática. Lo hicieron en el marco de la "guerra contra la subversión” y formó parte de su estrategia contrainsurgente. Desde la mentalidad militar, la "transición a la democracia" fue el resultado de un proceso de cambios en la visión política y estratégica de un sector de las fuerzas armadas (Sala, 2018b). La "implantación” inicial de las instituciones democráticas a partir de 1985 requería, a su vez, mayores transformaciones en una institución deslegitimada y fragmentada. ${ }^{2}$ Para encarar la transición, el sector estratégico del ejército, instalado en el alto mando de la institución y liderado por el general Héctor Alejandro Gramajo Morales, elaboró la Doctrina de Estabilidad Nacional (en adelante DEN) puesta en marcha a partir de la alianza entre este sector militar y el gobierno de Vinicio Cerezo Arévalo de la Democracia Cristiana (1986-1991). ${ }^{3}$ ¿Cuáles son los planteamientos más importantes de la

${ }^{1}$ Discurso de despedida del general Gramajo, mayo de 1990. Traducción propia: "As actors in this democratization process, we are convinced that to preserve democracy, it is necessary to protect it. Here lies the importance of the armed forces as a guarantor of the survival of the State." Citado en Schirmer (1991b, p. 11).

${ }^{2}$ La idea de "implantación de las instituciones democráticas" de Edelberto Torres-Rivas (2007) refiere a que el tránsito a la democratización política ocurre, más que por el desarrollo de condiciones socioeconómicas para una democracia, por la implantación de instituciones propias de la democracia liberal.

${ }^{3}$ El general Gramajo fue director de operaciones del Estado Mayor General del Ejército (EMGE) entre 1976 y 1978; subdirector de la Escuela Politécnica (1978-1979) y coordinador del sexto curso de Comando y Estado Mayor del Centro de Estudios Militares (1980). Ejerció la subjefatura del EmGe durante la dictadura 1982-1985. Durante el gobierno de Vinicio Cerezo, considerado el primero de la transición a la democracia, fue jefe del Estado Mayor de la Defensa Nacional (1986) y ministro de la Defensa Nacional (de febrero de 1987 a mayo de 1990). Es uno de los líderes del sector estratégico de las fuerzas armadas. La categoría "estratégicos" para designar a este sector militar -junto con otras como "institucionalistas"- comenzó a ser usada con fre- 
DEN?, ¿cuáles son las transformaciones que introduce?, ¿cómo se construyó?, ¿a partir de qué elementos del debate político?, ¿cuáles son los aspectos propios del pensamiento militar guatemalteco que incorpora y reformula? Este artículo propone un acercamiento a la DEN con el fin de aportar al estudio de los cambios en la mentalidad de las fuerzas armadas y, a través de ello, al proceso que Edelberto Torres Rivas (1991) denominó "transición autoritaria a la democracia" en Guatemala; cuyos antecedentes se remontan hacia fines de la década de los setenta, en un contexto marcado por la crisis del orden político, el quiebre de las alianzas tradicionales, el fraccionamiento y la descomposición de la propia institución militar, una imagen internacional fuertemente deteriorada por las violaciones a los derechos humanos, y un "conflicto armado" que distaba mucho de la victoria de las fuerzas armadas. En ese marco, surge en el seno de la propia institución una disputa interna que culminó en el derrocamiento del general Lucas García en 1982, mediante un golpe de Estado liderado por el sector estratégico de los militares. ${ }^{4}$ Este sector elaboró una política represiva feroz cuya máxima expresión fue el "genocidio" y, paralelamente, impulsó el proceso de transición a la institucionalidad democrática cuyo objetivo, además de la propia supervivencia de la institución, era ceder el ejercicio directo del gobierno a la clase política, continuar la contrainsurgencia, ganar la guerra, y mantener el control sobre la "seguridad nacional". La DEN es una nueva manifestación del cambio que venía operándose en la institución militar desde años atrás y se erige como el eje central a partir del cual se plantearon las transformaciones en la institución armada de cara a la transición de régimen político. En este texto atendemos a sus antecedentes y a los debates desencadenados en el proceso de reorganización del orden político que permearon en su proceso de elaboración y analizamos las concepciones más importantes de la DEN, desarrolladas a partir de las ideas de "estabilidad-bienestar", "integralidad", "oponentes" y "fundamentalismo

cuencia en los medios de comunicación a partir de la entrada en la escena pública de Gramajo. Es usada, asimismo, por varios analistas y, también, por los mismos oficiales "estratégicos". Aquí la retomamos porque consideramos que logra dar cuenta de una diferencia sustancial con la otra corriente importante de las fuerzas armadas, "los conservadores", frente a los que disputan el control de la institución: aquellos incorporan el pensamiento estratégico y el pragmatismo, mientras estos se mantienen en una posición inflexible respecto al lugar de los militares en la sociedad, la forma de llevar adelante la guerra y el gobierno del país. He trabajado sobre el pensamiento de los militares estratégicos en el periodo 1978-1986 en Sala (2018b). En ese mismo trabajo analicé las divisiones entre "estratégicos" y "conservadores" en las que se apoya este artículo.

${ }^{4}$ Para mayor información sobre este proceso histórico, véase Figueroa Ibarra et al. (2013). 
militar”. Afirmamos que de allí surge la propuesta más importante de la DEN, que implica un nuevo rol político para el ejército en la sociedad: proteger la democracia desde el cuartel; una democracia adaptada a las necesidades del proyecto estabilizador. Por cuestiones de espacio, dejamos para otro momento el análisis detenido en torno a dicho proceso de cambio político en el que surge la DEN y las disputas internas y las alianzas que impulsaron-obstaculizaron su implantación en la institución armada y su desarrollo como proyecto político a nivel nacional.

A pesar de la importancia que tuvo la DEN al interior de la institución armada y a nivel nacional, ha sido muy poco estudiado. Los dos trabajos más significativos son los de Héctor Rosada Granados (2011) y Jennifer Schirmer (1991a, 1991b, 1996, 1999). Ambos abordan la Tesis de Estabilidad Nacional (TEN) como una etapa dentro del "proyecto político" de los uniformados en el largo plazo; sus trabajos parten de la "perspectiva del actor" (Bustamante, 1986; Canelo, 2008). Rosada Granados, desde la sociología política, indaga en la forma en que los militares, en tanto actores con intereses corporativos, llevan adelante cambios en su proyecto político para permanecer en la esfera de poder. La TEN es, desde su mirada, "la opción ideológica de recomposición hegemónica" ante la crisis de hegemonía del bloque en el poder. Según Rosada Granados, la génesis del proyecto militar se ubica entre 1963 y 1982, su consolidación entre 1982 y 1987 y su agotamiento entre 1987 y 1990 . Para el autor, la TEN forma parte de la etapa de consolidación en la cual se forja "una nueva actitud mental en las Fuerzas Armadas" asentada en el respeto a la ley y el profesionalismo (Rosada Granados, 2011, p. 182); ${ }^{5}$ su enfoque enfatiza en la transformación militar. Schirmer, por su parte, aporta una mirada antropológica, basada en entrevistas a militares, desde la cual analiza el pensamiento de los oficiales respecto a la democracia, la seguridad y los derechos humanos. La antropóloga se refiere a la "apropiación del discurso democrático" por parte de los militares guatemaltecos como una forma de legitimar su accionar ante la opinión internacional y salvar la integridad de la institución. La autora acepta los dichos de Gramajo respecto a que los cambios reflejados en la TEN son más bien "una cuestión semántica a la cual nos debimos adaptar dado que estaba ocurriendo en el ambiente internacional" (Schirmer, 1996, p. 106). Más que hablar de transformaciones en las concepciones militares

${ }^{5}$ Otros analistas enfatizan en el gobierno de Arana Osorio (1970-1974) como un momento de consolidación del proyecto militar. Véase, por ejemplo, Poitevin (2000). 
como Rosada Granados, Schirmer resalta los aspectos de continuidad y considera que el planteamiento de la DEN es una apropiación discursiva engañosa para incorporar la contrainsurgencia en el régimen democrático y evitar la crítica internacional y la pérdida de legitimidad interna. En el caso de Rosada Granados, el enfoque está puesto en los militares como grupo de poder autónomo que actúa en pos de intereses exclusivos de las fuerzas armadas; mientras que, para Schirmer, los militares constituyen una institución con una "subcultura" y una racionalidad propia que explican su accionar. Ambos trabajos, clásicos en el estudio de los militares guatemaltecos, escritos en el auge de las teorías de las relaciones cívico-militares y en momentos de efectiva disputa para subordinar políticamente a los militares, matizan las disputas internas y las líneas de continuidad y mutuo condicionamiento entre fuerzas armadas y sociedad. ${ }^{6}$ Nuestro enfoque entiende a las fuerzas armadas como actores sociopolíticos con relativa autonomía, pero condicionados por el entramado social concreto en el que se mueven (Rouquié, 1984). Esta relación entre la institución y el entramado social que habita, no escapa a los aspectos doctrinarios. En su definición de doctrina militar, Ernesto López $(1985,1987)$ ha señalado la influencia que sobre ella tienen actores y procesos externos a la institución militar. López identifica cuatro ejes alrededor de los cuales se establece una doctrina: una concepción de los conflictos más importantes a los que está expuesta la nación; una concepción de la nación; una concepción acerca de la relación que debería mantener el ejército con el sistema político, y elaboraciones sobre la organización militar y lo específicamente bélico. Los tres primeros corresponden a proposiciones políticas. Esa presencia de elementos no exclusivamente militares implica que los uniformados no sean autosuficientes en materia doctrinaria. Según López (1985), "Están mucho más abiertos a la influencia del medio que otras instituciones de naturaleza organizativa parecida, como la Iglesia” (p. 105). Siguiendo la mirada de López, en este trabajo planteamos que la DEN se nutrió de los debates políticos locales, regionales e internacionales en torno a la democracia, la "transición", las rela-

${ }^{6}$ Dentro de las vertientes clásicas de la sociología militar, la que se inaugura con Samuel Huntington (1995) se caracteriza por enfatizar en la autonomización de la institución armada respecto del resto de la sociedad, mientras que la iniciada por Morris Janowitz (1967), propulsa la idea de integración. Fue Janowitz quien se interesó por identificar las características socioeconómicas, políticas y culturales que los militares compartían con otros sectores de la sociedad a la que pertenecían y que contribuían a definir su profesionalismo. Llamó civilinización al proceso por el cual estas incorporan lógicas y prácticas del mundo civil en el ámbito castrense (Soprano, 2013). 
ciones cívico-militares, las "nuevas amenazas" y la "gobernabilidad" en boga en ese contexto. Todos estos debates permearon la institución armada y fueron absorbidos y reformulados por el sector estratégico del ejército.

En términos generales, la DEN reformula la visión del orden social dentro de la doctrina de las fuerzas armadas y la relación de estas con el Estado y la sociedad. Replantea los marcos político-conceptuales y técnico-militares a partir de los cuales este sector militar pretendió guiar a la institución en el contexto de una situación inédita: un proceso de "transición a la democracia" en el marco de una larga "guerra contra la subversión". Para ese fin, busca reformar la organización interna de las fuerzas, guiada a través de la idea de "fundamentalismo militar". La DEN constituyó, asimismo, un programa político de transición -apoyado e impulsado por el gobierno de Cerezo- que pretendía involucrar e integrar a todos los "poderes" en una "democracia protegida" con un rol específico y "trascendental" para los militares: "proteger la democracia" desde el cuartel.

Este artículo se divide en dos apartados de desarrollo y las conclusiones finales. La primera parte realiza un breve recorrido por los antecedentes de la DEN y por los debates y procesos de diálogo e intercambio que permearon en su elaboración. En la segunda parte, se estudia el contenido y los planteamientos más importantes del proyecto de la DEN. Para ello se apoya en varias fuentes, siendo las principales la TEN escrita por el general Héctor Alejandro Gramajo y publicada en 1989 por la Editorial del Ejército, la manifestación más explícita de la Doctrina de Estabilidad Nacional y las Directivas del Estado Mayor de la Defensa Nacional 3 -"L"-M-RAJAE de febrero 1986 (citado en Gramajo, 1995, pp. 247-248) y 3 -"L"-M-RAJAE-I-87 de diciembre de $1986^{7}$ donde se operativiza la idea de "fundamentalismo militar". En estas directivas se establece la estrategia militar para normar el empleo, administración y desarrollo del ejército en el marco de la nueva doctrina, de ahí la importancia de las mismas en este trabajo. También se utilizan entrevistas realizadas por la autora y otras publicadas; discursos, publicaciones y tesis de Gramajo y otros oficiales superiores del ejército que sirven para ilustrar los debates que dieron forma a la DEN.

7 Directiva núm. 3 -"L"-M-RAJAE-I-87. Diciembre de 1986. Colección EMP, GT-DAPPR-01-07-S010-04, 1986, 1. Archivo Histórico General de Centroamérica (en adelante AHGC), ciudad de Guatemala. 


\section{LA ELABORACIÓN DE LA DEN, SUS ANTECEDENTES Y LOS DEBATES QUE LA NUTRIERON}

Al igual que Rosada Granados, consideramos que la DEN refleja un cambio en las concepciones militares, impulsado por el sector estratégico del ejército, y no un engaño semántico. La DEN tiene sus antecedentes en, por un lado, el proceso de reflexión que confluyó en el Plan Nacional de Seguridad y Desarrollo (PNSD) de 1982. Como hemos analizado en otro trabajo (Sala, 2018b), el PNSD es resultado del proceso de reformulación de los supuestos en los que se apoyaba el pensamiento militar desde, al menos, el golpe de Estado contra Jacobo Arbenz en 1954. Esta reformulación abarcó tres tópicos centrales: el replanteamiento del "problema subversivo" (sus causas, características y respuestas a la "guerra subversiva"), el profesionalismo militar, y una reflexión práctica sobre los peligros de ejercer el gobierno político. El PNSD da cuenta de una lectura profunda de los postulados de la seguridad nacional de los militares sudamericanos de los años sesenta, fundamentalmente la idea de integralidad y participación de todos los "factores de poder nacional" (al respecto véanse Rostica, 2018; Sala, 2018a). A partir de estas reformulaciones el ejército comenzó un proceso de cambios al interior de la institución y en la forma de llevar adelante la guerra, que desembocarían en el genocidio, $y$, paralelamente, en la transición al régimen democrático en tanto estrategia contrainsurgente. La DEN expresa los reajustes a ese marco conceptual militar en el contexto de un nuevo momento político originado con el triunfo presidencial de Vinicio Cerezo Arévalo y la inauguración del llamado "primer gobierno de la transición". Las ideas que comenzaron a dar forma al proyecto de la DEN convergieron en un conjunto de reflexiones que se desataron en el Seminario para Comandantes de Zonas Militares en 1986. Una primera manifestación pública de esas ideas se llevó adelante en 1987, en el foro 27 Años de Lucha por la Libertad, organizado por el consejo empresarial, donde el alto mando del ejército, liderado por el sector estratégico, expuso sus reflexiones y su proyecto a la burguesía nacional. ${ }^{8}$ En ese foro, los militares plantearon que las preocupaciones centrales del Estado en ese momento eran la "estabilidad nacional y el bienestar

${ }^{8}$ Expusieron el subjefe del EMDN, general Juan Leonel Bolaños Chávez, el director de Operaciones del EMDN, coronel Mario Rolando Terraza Pinott, el director de Asuntos Civiles del EMDN, coronel Mario René Enríquez Morales y el ministro de la Defensa, general Héctor Gramajo. 
ciudadano". Se apeló, en términos de enfoque estratégico y retomando el PNSD de 1982, a la participación de todos los sectores "con el fin de que todos, con más decisión, compartan responsabilidades". Para lograr la estabilidad y el bienestar se requerían acciones da cada uno de los factores de poder nacional "haciéndose necesario que las clases dirigentes del país contribuyen exhaustivamente a consolidar el sistema de vida democrático", a lograr un desarrollo económico y seguridad. El desarrollo económico y la cuestión social, afirmaron los ponentes, resultaba clave para frenar a la "delincuencia terrorista"."

La DEN se nutrió, asimismo, de los debates políticos locales, regionales e internacionales en torno a la democracia, la "transición", las relaciones cívico-militares, las "nuevas amenazas" y la "gobernabilidad", en boga en ese contexto. Todos estos debates permearon la institución armada y fueron absorbidos y reformulados por el sector estratégico del ejército. En este aspecto, fueron importantes los cursos de Comando y Estado Mayor del Centro de Estudios Militares, desde donde se difundieron y profundizaron..$^{10}$ Asimismo, contribuyeron las participaciones de Gramajo y otros oficiales en foros, seminarios y talleres, y en las instancias de diálogo civil-militar impulsadas por las academias estadunidenses y sudamericanas. En mayo de 1988, Gramajo participó en la Conferencia sobre Relaciones Cívico-Militares en América Latina, en la American University, donde se reunieron militares, políticos y académicos. En junio de 1989, cuando Gramajo era ministro de Defensa, el Centro de Estudios Militares, junto a la Asociación de Investigación y Estudios Sociales de Guatemala (AsIes), la American University y el centro peitho (Montevideo, Uruguay), patrocinaron el seminario El Desafío de las Relaciones Cívico-militares en Centroamérica Durante la Transición a la Democracia, en la ciudad de Guatemala. El encuentro estuvo ampliamente

9 Véase el foro nacional 27 Años de Lucha por la Libertad. Transcripción del foro nacional, organizado por el consejo empresarial, 27 Años de Lucha por la Libertad, una presentación oficial del Ejército de Guatemala. Colección ICA núm. 1485. Archivo Histórico. Centro de Investigaciones Regionales de Mesoamérica (en adelante Archivo histórico cIRMA), Antigua, Guatemala.

${ }^{10}$ Los títulos de las tesis de Curso de Comando y Estado Mayor reflejan los debates vigentes entre la oficialidad, por ejemplo: "Educación militar en los oficiales para fortalecer la democracia actual en el país" (1988); "Introducción a la guerra política en el Ejército de Guatemala" (1988); "Posición del ejército en un gobierno democrático"; "Importancia del ejército como garante de la seguridad del Estado" (1988), entre otros, en Catálogo de tesis de Curso de Comando y Estado Mayor. Biblioteca del Estado Mayor de la Defensa Nacional, ciudad de Guatemala. Consultado en septiembre-noviembre de 2016. 
publicitado, en tanto fue la primera vez que se realizaba un evento de esta naturaleza teniendo a los militares como anfitriones.

Ese mismo año se publica la Tesis de Estabilidad Nacional (TEN) y, a instancias de Gramajo y de la Fundación para el Desarrollo Institucional de Guatemala (DIG), se crea el Centro de Estudios Estratégicos para la Estabilidad Nacional (ESTNA), cuyo objetivo inicial era crear una elite civil-militar calificada, capaz de llevar adelante el proyecto de estabilidad nacional. ${ }^{11}$ Con conexiones e influencias de instituciones estadunidenses como la USAID, y considerado por algunos como un think tank del ejército, el ESTNA se caracterizó por el dictado del Curso de Estudios Estratégicos Nacionales al que se invitaba a participar a dirigentes políticos, académicos, indígenas y sindicales. ${ }^{12}$ Este centro se constituyó en un espacio de difusión de las diversas tesis sobre las relaciones cívico-militares en los nuevos regímenes democráticos y de saberes en torno a "planificación estratégica", a través del cual se buscaba consolidar el "retorno a los cuarteles" y la implantación de la institucionalidad democrática.

En este marco, los militares estratégicos elaboraron una nueva significación, conservadora y autoritaria, del conflicto social, de la democracia y de la función militar en la sociedad. Significaciones que disputaron con otros sentidos de democracia y de orden social, en un contexto de reformulación del orden político en el país. En este punto concordamos con Schirmer, quien sostiene que la propuesta militar plasmada en la DEN logra borrar la contradicción entre democracia y "contrasubversión" que caracterizó, por ejemplo, la transición democrática en Argentina.

\section{LA DOCTRINA DE ESTABILIDAD NACIONAL}

\section{De la seguridad a la estabilidad}

En la elaboración de la TEN los conceptos "estabilidad y bienestar", más que "seguridad y desarrollo", representan el horizonte de la transición. Según Gramajo (1989) ello responde a que:

${ }^{11}$ Centro estna, Curso 1989-1990. Colección Infostelle, signatura 81. Archivo histórico CIRMA, Antigua, Guatemala.

${ }^{12}$ Véase al respecto la entrevista al general Julio Balconi en Kruijt y Van Meurs (2000, p. 99). 
estamos en un estado tan primitivo del subdesarrollo, que no somos, como se nos califica amablemente, un país en vías de desarrollo. En base a esa conclusión, descartamos usar el concepto de seguridad y desarrollo y optamos quedarnos en la escala anterior de estabilidad y bienestar. Si logramos estas metas, después podremos alcanzar el nivel siguiente de seguridad y desarrollo (p. 9).

Esta concepción del binomio estabilidad-bienestar como paso previo a la seguridad-desarrollo indica su transitoriedad y su adecuación para pensar el proceso de transición. En la tesis, la "estabilidad nacional" queda resumida de la siguiente manera:

Estabilidad nacional son todas las medidas en los campos sociales, económico, militar y político, que nuestra sociedad ejecuta para generar en los habitantes de Guatemala una actitud psicológica propicia para buscar su bienestar. Que disponga a Guatemala para un grado superior de desarrollo, que con el tiempo traerá la completa seguridad, a pesar de las acciones contrarias de los oponentes del Estado (Gramajo, 1989, p. 45).

Gramajo (1989) se preocupó en aclarar que la estabilidad no debía entenderse como mantenimiento del statu quo, sino como la "capacidad de un sistema político para durar en el tiempo” (p. 43). Esta noción de estabilidad se desenvolvió entre la racionalidad propia del desarrollismo autoritario latinoamericano de los años sesenta, asociada a las ideas de seguridad nacional (Devés Valdés, 2003) y de "gobernabilidad", que comenzarían a cobrar auge por esos años. La idea de gobernabilidad, planteada originalmente por la "Comisión Trilateral" en 1975, señalaba que la sobrecarga de demandas provenientes de la sociedad hacia el sistema político ponía en riesgo la estabilidad de las democracias. Este planteamiento es complementado en la DEN con la idea del subdesarrollo como causa fundamental de las demandas sociales esbozada previamente en el PNSD. La estabilidad y el bienestar, como la seguridad y el desarrollo, se encuentran en una relación dialéctica: una es condición de realización de la otra. ${ }^{13}$ El planteamiento de la DEN detallado en la TEN es muy esquemático. Retoma las ideas del PNSD, en el cual las causas del conflicto no son meramente externas, no tienen que ver sólo con la penetración del comunismo internacional. Los factores internos, como las "injusticias sociales", los

${ }^{13}$ Sobre el discurso de la gobernabilidad, véanse Camou (2010) y Torres Rivas (1993). 
"desequilibrios económicos", la "exclusión política", habían configurado un escenario conflictivo que la insurgencia comunista aprovechó. Con base en ese diagnóstico inicial, y habiendo avanzado en la resolución de la "causa política" a través de la democracia representativa, restaba fortalecer y proteger las instituciones y alcanzar el desarrollo para resolver las causas económicas y los conflictos derivados de ellas. Para tal fin se identifican los "objetivos nacionales" a largo plazo: desarrollo y seguridad, los cuales representan el estado ideal al que se debe aspirar, y para alcanzarlos se requiere la participación e integración de todos los poderes de la sociedad (militar, económico, social y político), aplicando las políticas de desarrollo, seguridad y cultural necesarias para generar una "actitud psicológica propicia para buscar su bienestar". Es decir que el desarrollo y la seguridad requieren de la conformación de sujetos aptos, con "actitud psicológica propicia", de la domesticación, sujeción y control del sujeto para que se disponga a buscar "su bienestar".

Según Gramajo (1989), la Doctrina de Seguridad Nacional (DSN) que la DEN viene a reemplazar, invisibilizaba las causas del conflicto, negándolo; por esa razón se desechó, "por su carácter negacionista" y su mentalidad puramente represiva. Como se sugiere en la TEN, el planteamiento de la DSN "es correcto y lógico en un país con un mayor grado de desarrollo, desarrollo que deben cuidar, porque todos sus habitantes tienen niveles aceptables de satisfacción" (p. 36). Por ello, la DSN apunta a la conservación del statu quo de las instituciones que garantizan el desarrollo. En Guatemala, según los militares estratégicos, esas instituciones están en proceso de creación (en el marco de la transición), con lo cual la DSN no es apta para un país en estado de subdesarrollo, en tanto conservaría un statu quo que no garantiza el bienestar de la mayoría, y es en el estado de subdesarrollo donde justamente radican las causas del conflicto.

En un estado de no-desarrollo los conflictos devienen importantes y provienen de los "oponentes del Estado". Bajo esta lógica, la estabilidad es la capacidad de mantener el(un) orden social en un contexto de no-desarrollo para justamente permitir, con la participación de todos los poderes, el desarrollo, el cual, según este razonamiento, conduce a la eliminación del conflicto, y el no-conflicto es la plena seguridad. Una vez alcanzado el desarrollo, es decir el no-conflicto, la seguridad no estaría interpelada por causas internas, sino externas a la sociedad-Estado. Alcanzado el desarrollo, la seguridad se reduciría al mantenimiento del (de un) orden social, ahora sí, al mantenimiento del statu quo. 


\section{De enemigos a oponentes}

En la DEN, el conflicto -cuya causa última es el no-desarrollo- deviene de los "oponentes" o "antagonismos" que, a su vez, impiden el desarrollo. Se abandona el término "enemigo" planteado durante el periodo anterior; ahora el "oponente" es quien (o lo que) impide alcanzar los objetivos nacionales de bienestar y estabilidad (pasos previos al desarrollo y la seguridad). Hace falta, entonces, superar "los antagonismos que se identifican sean en el campo interno o internacionales, sean en el frente de la seguridad o del desarrollo, como factores contrarios a la consecución y salvaguarda de los objetivos nacionales permanentes" (Gramajo, 1989, pp. 22-23).

En entrevista con Jennifer Schirmer, el capitán de navío Jorge Arturo Mazariegos, autor de El Estado, su estabilidad y el desarrollo de una Estrategia Nacional de 1990, sostuvo:

nosotros planteamos lo que produce oponentes: condiciones peculiares de pobreza, alto índice de analfabetismo. Como ejemplo aquí: carencia de lo esencial, alto crecimiento demográfico, presencia de extranjeros indocumentados que utilizan fuentes de trabajo... que provocan tasas más altas de desempleo y por otro lado mayor consumo de granos básicos (Mazariegos citado en Schirmer, 1999, p. 394).

Los oponentes están divididos en categorías organizadas según su creciente grado de amenaza. Así, como relata Mazariegos, según el grado de influencia que tiene puede ser un factor adverso, después puede pasar a ser vulnerabilidad, después puede pasar a ser antagonismo, hasta que llegue a presión (Schirmer, 1999, p. 393). Las "presiones" son todos aquellos oponentes del Estado o antagonismos que cuentan con un poder de respaldo o apoyo para tratar de imponerse: "Presiones dominantes o amenazas" son todas aquellas presiones cuyo poder supera al nacional, o que siendo comparable representan una situación inestable (Gramajo, 1989, p. 25). Ante una presión dominante se tiene que aplicar el "poder militar"; la idea de "presión dominante" viene a reemplazar al concepto de "enemigo interno" en los términos planteados en el Manual de guerra contrasubversiva del ejército de Guatemala. ${ }^{14}$

${ }^{14}$ Ejército de Guatemala. Manual de guerra contrasubversiva elaborado por la Escuela de Comando y Estado Mayor del CEM para fines de instrucción [TE-06-1]. Guatemala: Centro de Estudios 
La idea de oponente matiza -no niega- la relación amigo-enemigo. Frente al enemigo no hay alternativa, supone la eliminación. Frente al oponente, de acuerdo con su nivel, existen variables de acción. El término "oponente" se configura, de esta manera, en la versión matizada "para la democracia" de la concepción de enemigo interno. La clasificación "amigo-enemigo" tiene ahora intermedios. Con el matiz que introduce la idea de oponente, mientras el conflicto se manifieste en un nivel bajo, como "factores adversos", los medios para combatirlos no son militares, sino políticos. La solución no debe ser la eliminación (100\% fusiles) por parte del aparato militar, sino que deben intervenir otros poderes con lógicas no militares. Esto implica cierto grado de aceptación de la dinámica conflictiva de la democracia, aunque, claro está, mientras se mantenga dentro de los límites aceptables por los militares, y hasta tanto se alcance el desarrollo. Ello garantiza la estabilidad. En la tesis para ascender de grado: Influencias de las corrientes ideológicas en el ejército el autor plantea que "los oficiales deben tener un grado de educación suficiente, que les indique la importancia de la actividad política en la liberación de las tensiones, la satisfacción de demandas y la reducción de conflictos antes que deriven en violencia". ${ }^{15}$

Como sostiene Mazariegos, los oponentes en estado de factores adversos deben ser tratados con medidas no militares:

Aquí las medidas deben ser políticas, económicas y sociales para evitar que lleguen a este nivel más alto y tengamos que utilizar el poder militar [...] Lo que se debe hacer es combatir a estos oponentes a nivel de desarrollo, de mejores salarios, a nivel de pláticas entre trabajadores y propietarios para que sea más justo para todos, ipero no al grado de hacer quebrar la fábrica! Esto implica penetración mutua de conciencia y educación (Mazariegos citado en Schirmer, 1999, p. 394).

En el contexto desatado con el gobierno de Cerezo, el sector estratégico del ejército amplió su margen de acción respecto a los oponentes del Estado, que siguió siendo, como en la DSN, sinónimo de sociedad. Ya no se restringía al

Militares, sin fecha. Biblioteca del Estado Mayor de la Defensa Nacional. Consultado en noviembre de 2016.

${ }^{15}$ I-77-IV-88. Influencias de las corrientes ideológicas en el ejército. tesis de ascenso, febrero de 1988. Guatemala: Centro de Estudios Militares, p. 2. Biblioteca del Estado Mayor General del Ejército. Ciudad de Guatemala. 
"enemigo subversivo", devenido "delincuente terrorista", concepto que apunta a destacar su calidad de ilegal en el marco de la democracia. En este nuevo contexto, Gramajo (1989) identificaba que los oponentes del Estado eran:

a) El contrabando; b) la subversión: del marxismo-leninismo y del conservatismo extremo y radical; $c$ ) las huelgas, manifestaciones violentas, la agitación en general; d) el narcotráfico; e) el tráfico de influencias; f) la inmigración clandestina o solapada. Y las vulnerabilidades son: a) la corrupción; $b$ ) la falta de educación cívica y general; c) bajo nivel de principios, disciplina y medios de las fuerzas de seguridad; $d$ ) deuda Externa; $e$ ) incapacidad de repatriar capital generado por la producción nacional (pp. 24-25).

El enemigo subversivo es uno entre varios nuevos oponentes. Lo que caracteriza esta concepción es la amplitud que va desde la subversión al orden establecido, tanto marxista como la del "conservatismo extremo-radical", y delitos como el narcotráfico hasta la deuda externa. Al ampliar las causas del conflicto, bajo una mirada que intenta eliminarlo, se amplían los "oponentes". Este planteamiento recupera los debates respecto de las "nuevas amenazas” en boga durante el periodo. Según Aguilera Peralta (2008), el concepto de "nuevas amenazas" se origina en dos fuentes. En primer lugar, pertenece al debate sobre la seguridad que tuvo lugar en las transiciones del Cono Sur; allí se buscó reemplazar la DSN por concepciones que trasladaran el núcleo problemático de la seguridad desde la preservación del Estado-nación (propio de la DSN) hacia la democracia y el bienestar. Ello implicaba ampliar la identificación de las amenazas a otras cuestiones como la pobreza, el medioambiente, el desempleo, la marginalidad, etc. A estos nuevos riesgos se los denominó "nuevas amenazas" a fin de diferenciarlos de las tradicionales. La segunda fuente de las "nuevas amenazas" proviene de diversos centros de poder, especialmente de Estados Unidos, en el marco del fin de la guerra fría. De esta línea, las "nuevas amenazas" se identifican con el "terrorismo" y el crimen organizado, en especial la narcoactividad.

En todo este planteamiento pervive una concepción de la democracia restringida al funcionamiento de las instituciones, que niega lo intrínseco de toda democracia sustantiva, el conflicto. Este es sólo aceptado mientras se mantenga limitado y mientras subsista el subdesarrollo. La clasificación de un conflicto como "presión dominante o amenaza" habilita el uso de la fuerza militar para alcanzar su eliminación. Así, se plantea una democracia limita- 
da al funcionamiento de ciertas instituciones, compatible con la eliminación de los nuevos enemigos: oponentes clasificados como amenazas; es decir, un régimen político democrático-contrainsurgente. ${ }^{16}$ Ello sugiere la necesidad de problematizar el binomio opositor "autoritarismo-democracia" planteado en las teorías de las relaciones cívico-militares, y analizar las configuraciones de sentido que fue adquiriendo la idea de democracia y las formas de su institucionalización para poder pensar el proceso histórico de reorganización del orden político en Guatemala.

\section{Integralidad, participación y poder militar}

La TEN, al igual que el PNSD, postula que para alcanzar la estabilidad que lleve al país al desarrollo y a la seguridad, se requiere la integración y participación de todos los "poderes nacionales". La idea de integralidad está representada en el símbolo que representa la Estabilidad Nacional, y que ilustra la tapa de la tesis: una estrella de cinco puntas con una intersección bien delimitada. El coronel retirado Jorge Antonio Ortega Gaytán comenta: "Esta vaina [refiere a la estrella de cinco puntas] la usábamos acá en la solapa, todos los egresados y los maestros. Este era el símbolo". ${ }^{17}$

Esta apelación a la integralidad tiene que ver, como ya indicamos, con la forma en que se percibe el conflicto y sus causas y, por otro lado, con una visión nueva del "poder militar". La estabilidad es ahora responsabilidad de todos los sectores de poder, no sólo de los militares, quienes se constituyen en uno más de los varios factores que deben intervenir. En este sentido, como señala Aguilera Peralta (1994, p. 79), la estabilidad nacional se diferencia de la aproximación de la seguridad nacional anticomunista. Los militares se ven

${ }^{16}$ Nos basamos aquí en el concepto de "poder contrainsurgente" de Edelberto Torres Rivas (1998). Los datos de violaciones a los derechos humanos a partir del gobierno de Cerezo son una muestra concreta de esta forma de organización del orden político. Véanse al respecto CEG (1995). Según Carlos Figueroa Ibarra (1999), durante el gobierno de Vinicio Cerezo Arévalo (1986-1990) las cifras de desaparecidos alcanzaron en algunos años dimensiones parecidas a las del gobierno del general Carlos Arana Osorio (1970-1974) y son superiores a las del periodo del general Kjell Laugerud (1974-1978). En iguales términos puede hablarse del gobierno de Jorge Serrano Elías (1990-1993), cuyo primer año, con 147 casos de desaparición forzada, es más elevado que cualquiera de los años de gobierno del general Laugerud.

${ }_{17}$ Entrevista al coronel retirado Jorge Ortega Gaytán, realizada por Laura Yanina Sala, ciudad de Guatemala, 26 de febrero de 2016. 
como un actor más dentro de la lucha contrainsurgente, de la seguridad en general y de los planes de desarrollo. Las constantes alusiones de Gramajo respecto a que el ejército "es una institución más del Estado" iban en ese sentido.

La DEN delimita el "poder militar" como aquel que "usa los medios específicamente militares y actúa tanto en el campo externo como en el campo interno" (Gramajo, 1989, p. 29). En el campo interno, el poder militar interviene para garantizar la seguridad y la paz interior reduciendo o anulando antagonismos y presiones (Gramajo, 1989, p. 29). ¿A qué se refiere con "específicamente militares"? En la DEN, lo "específicamente militar" se limita a diferenciar el ámbito militar (que incluye funciones de control social y orden público, asuntos civiles, construcción de caminos, etc.) de la arena política institucional. Los militares ya no deben ocuparse del poder político, deben ceder el control político "a los políticos" y fortalecer el aspecto "puramente militar". Aquí radica la otra base de la DEN, lo que se denominó el "fundamentalismo militar", que debía guiar las transformaciones internas de la institución. Veamos de qué se trata.

\section{De guerreros a soldados. El "fundamentalismo militar"}

El proyecto del sector estratégico del ejército para esta etapa de "transición" implicaba, en primer lugar, el abandono por parte de la institución militar de sus funciones políticas de control del gobierno, lo que requería un reacomodo en su interior. En sus diversas intervenciones, Gramajo se encargaba de remarcar la importancia de comprender el cambio y la necesidad de adaptarse a la nueva época. En su discurso en ocasión de los 116 años del ejército, Gramajo afirmaba:

sabe el Ejército que todo proceso de modernización, en el cabal sentido de la palabra significa renovación... de lo malo a lo bueno; de lo bueno a lo mejor; de lo mejor a lo superior... Para esto es indispensable un cambio de mentalidad, pero para renovarse hay que exponerse; incluso, hasta a las críticas sin juicio ni fundamento [...] Está el Ejército como toda la nación en plena actividad remodeladora, estamos revisando... reajustando... renovando... agilizando... no solo en lo material, sino desde todo aquello que la flexibilidad permite dentro de los cánones disciplinarios y jerárquicos. ${ }^{18}$

${ }^{18}$ Discurso del ministro de Defensa Héctor Alejandro Gramajo Morales, 30 de junio de 1987, pp. 4-5. Fondo ICA, núm. 1484. Archivo histórico CIRMA, Antigua, Guatemala. 
Si bien la idea de "fundamentalismo militar" estaba presente en los documentos oficiales al menos desde la "Directiva del Estado Mayor para la Normalización Institucional Militar” de 1983, la vuelta al cuartel luego de entregar el gobierno a Cerezo amplió su significado y las posibilidades de llevarla a cabo. Una vez acordado el traspaso de gobierno al presidente "civil", el alto mando se embarcó en un proceso de reorganización guiado por la idea de "fundamentalismo militar" según la cual las fuerzas armadas debían "profesionalizarse", afianzar una autoridad militar interna fuerte y actuar conforme a las funciones establecidas por la ley y al margen de intereses políticos o individuales, para adaptarse a la nueva situación democrática. Se buscaba, según Gramajo (1995), "asumir una actitud religiosa hacia los asuntos militares", el comportamiento militar debía estar "cargado de conducta profesional, carácter y protocolo militares, así como de legalidad" (p. 245).

La "profesionalización" fue el concepto que utilizaron los militares estratégicos para delinear el proyecto de transformación hacia el interior de la institución. Gramajo, como comentamos previamente, estaba nutrido de la perspectiva de las relaciones cívico-militares. De ahí que el planteamiento del fundamentalismo, a tono con la idea de Samuel Huntington (1995) según la cual la profesionalización de los militares es inversamente proporcional a su participación política, proponía la "profesionalización" como la vía para hacer de los militares "profesionales de las armas" y alejarlos de la función política. La "profesionalización" mediante la "autonomía profesional", según Huntington (1995), implicaba un "control objetivo" del poder militar. ${ }^{19}$ Estas ideas guiaron el proyecto de estabilidad. La profesionalización propuesta apuntaba, centralmente, a profundizar la formación militar de cara a transformar los "valores operativos" que daban forma a su función en la sociedad, a fin de alejar a los militares en activo de la política institucional y a fortalecer los "valores organizativos": restablecer las jerarquías y centralizar el mando.

En Guatemala, la "profesionalización" se plasmó, en primera instancia, en las directivas 3 -"L"-M-RAJAE de febrero de 1986 (citado en Grama-

${ }^{19}$ Huntington inventó el término "control civil" con el objeto de reflexionar acerca de la reducción del poder militar. El "control civil", según Huntington, se puede lograr mediante dos formas: el control subjetivo y el objetivo. Mientras que el primero se refiere a la búsqueda de la subordinación mediante una adhesión particularista de los miembros de las fuerzas con los civiles, el segundo hace referencia a la obtención de la misma por intermedio de las normas legales del régimen. Los efectos del control subjetivo tienden a producir la politización castrense, mientras que el otro favorece su profesionalización. 
jo, 1995, pp. 247-248) y 3 -"L"-M-RAJAE-I-87 de diciembre de $1986 .{ }^{20}$ Ambas establecían que el ejército debía fortalecer la institución a través de la despersonalización de la autoridad a todo nivel, lo que fue definido como "liderazgo profesional", obedeciendo, cumpliendo y haciendo obedecer las leyes y reglamentos a todos los niveles de mando. Esta primera cuestión implicaba un cambio sustancial en las lógicas que guiaban las relaciones al interior de la institución. El "liderazgo profesional" planteaba una reformulación en los criterios y la práctica en torno a la autoridad y la lealtad. Desde la época de la revolución (1944-1954), la organización institucional y las políticas destinadas a mantener la obediencia del ejército habían estimulado un sistema de lealtades internas personalizadas que obedecían a intereses ideológicos, políticos, de negocios más que a lealtades de autoridad formal. El fuerte crecimiento de las estructuras de mando del ejército a comienzos de la década de los ochenta presionó aún más en aquel sentido. Los golpes de Estado de 1982 y 1983 causaron divisiones internas y el desarrollo de otras redes de lealtades entre los oficiales "operadores", por un lado, y los de "inteligencia", por otro, complejizando las relaciones en la institución.

Se buscaba, además, centralizar las decisiones operativas en materia de seguridad. La directiva de centralización cambiaba la forma en que se estaba llevando adelante la guerra. Así lo explica Cerezo:

nosotros tomamos una decisión. Y ahí empieza el tema de seguridad. Antes, todos los problemas que se produjeron al interior del país fueron porque había una doctrina estratégica en el Ejército que era "libertad operativa de cada Comandante en el interior del país”. Entonces, cada quien podía hacer lo que le diera la gana para ganar la guerra. Primer cambio que nosotros hacemos: eso no se puede. Tenemos que centralizar las decisiones para empezar a disminuir las violaciones a los derechos humanos. ${ }^{21}$

La formación pasó a ser un asunto central en el proceso de transformación institucional que encaró el alto mando. En este sentido, la directiva 3 -“L”-M-RAJAE-I para el año 1987, estableció como política, entre otras de

${ }^{20}$ Directiva núm. 3 -"L”-M-RAJAE-I-87, diciembre de 1986. Colección EMP, GT-DAP-PR01-07-S010-04, 1986, 1. AHGC, ciudad de Guatemala.

${ }^{21}$ Entrevista al expresidente de Guatemala, Marco Vinicio Cerezo Arévalo, realizada por Laura Yanina Sala, ciudad de Guatemala, 3 de febrero de 2016. 
tipo operativo para llevar adelante la guerra, la siguiente: "Hacer conciencia en la oficialidad de su carácter profesional y su condición de caballeros, para lo cual se hace necesario revisar y actualizar la filosofía educativa y de entrenamiento del Ejército de Guatemala, coordinando el ciclo educativo militar." ${ }^{22}$

El proceso de formación de los oficiales ocupó un lugar central. En la tesis Organización profesional del ejército de Guatemala como fuerza armada. Un reto fututo al alto mando del ejército, de agosto de 1986, el autor plantea: "La educación militar debe fortalecerse en el centro de estudios militares para tener un guerrero educado sin temor a lo que tradicionalmente se nos ha hecho creer, o en alguna forma se comenta, de que la educación debilita el espíritu Militar y combativo." ${ }^{23}$

El proceso de formación impulsado por Gramajo se mantuvo en el tiempo y fue uno de los mayores logros de los militares estratégicos. El militar retirado Jorge Ortega Gaytán comenta el proceso de esta manera:

[...] todo el esfuerzo fue en dirección a la profesionalización del estamento militar, el proceso de la educación paralela a los diferentes cuadros, el definir todo un proceso de educación dentro del Ejército: amarrar los básicos con la escuela politécnica, la escuela politécnica con el básico de infantería, el básico de armas, el avanzado de armas, operaciones, avanzados, el diplomado en Estado Mayor, de ahí el de Guerra Superior y luego el de Altos Estudios Estratégicos, y la Maestría. O sea, todo un proceso en la línea militar. Y paralelo a eso, pues, cualquier otra carrera liberal que le permitiera tener mejor herramientas para comandar al oficial, ¿verdad? Yo creo que ahí está el éxito. El éxito de la transformación del Ejército. ${ }^{24}$

22 Directiva 3 -“L”-M-RAJAE-I-87, Colección EMP, GT-DAP-PR-01-07-S010-04, 1986, 1. AHGC, ciudad de Guatemala. El glosario de la Directiva de marras define "carácter profesional" de la siguiente manera: es la facultad de actuar por medio de decisiones acertadas y justas, basadas en conocimientos, estudios, prácticas y técnicas continuas, aplicándose al mismo tiempo los principios de igualdad, justicia y equidad, en beneficio de la mayor eficiencia en el cumplimiento de la misión.

${ }^{23}$ I-52-X-86. Organización profesional del ejército de Guatemala como fuerza armada. Un reto fututo al alto mando del ejército. Tesis de ascenso, agosto de 1986. Guatemala: Centro de Estudios Militares, p. 49. Biblioteca del Estado Mayor de la Defensa Nacional, ciudad de Guatemala. Consultado en noviembre de 2016.

${ }^{24}$ Entrevista al coronel retirado Jorge Ortega Gaytán, realizada por Laura Yanina Sala, ciudad de Guatemala, 26 de febrero de 2016. 
Con todas estas medidas, el ejército se proponía el retiro de los órganos de gobierno. La directiva 3 -"L"-M-RAJAE establecía que:

Con el objeto de crear el espacio que permita a las instituciones y grupos de la sociedad civil ampliar su participación, el Ejército como una institución, y sus oficiales en servicio activo en forma individual, se retirarán de las actividades gubernamentales y de la participación en la política, no adoptarán posiciones, ni emitirán opinión en discusiones nacionales de asuntos económicos. [...] los oficiales deberán obedecer y apoyar las leyes de la nación, y las autoridades legalmente establecidas; [...] El Ministro de Defensa, por la naturaleza de su empleo, es el único oficial en servicio activo autorizado para comunicarse con los líderes e instituciones políticas, y del gobierno (Gramajo, 1995, pp. 247-248).

En 1986, el alto mando del ejército de Guatemala pretendía inculcar en los oficiales que "no le corresponde al Ejército intentar rescatar a la Nación de la injusticia social; los oficiales deberán dar el ejemplo al resto de la nación de cómo comportarse en una democracia" (Gramajo, 1995, p. 248). Se trataba de abandonar su función de "salvadores de la nación". El reto era grande si consideramos el accionar político de las fuerzas armadas durante gran parte del siglo xx en Guatemala. Los comandantes de zona estaban acostumbrados a dedicar más tiempo a la actividad política, a la administración pública y a las actividades de desarrollo que a las tareas puramente militares. De hecho, fue un proceso complejo y discontinuo el de quitarle funciones a la "Junta de comandantes". Esta junta estaba constituida por los jefes de las distintas bases militares ubicadas en los 22 departamentos del país. No era reconocida jurídicamente, pero desempeñaba, de hecho, un papel central en las decisiones políticas y militares del ejército. Según Rosada Granados (2011), fue necesario girar instrucciones específicas para que se comprendiera que la práctica de reunir al Consejo de Comandantes cesaría y que, en consecuencia, ningún mando militar ajeno al ministro de la Defensa Nacional participaría, junto al presidente de la república, para tomar decisiones en materia de política nacional, asuntos de seguridad y relaciones exteriores (p. 181).

En el corto plazo, el debate interno que desató la idea del fundamentalismo fue planteado por Gramajo (1995) en los siguientes términos: "si el Ejército era anticomunista, como nos lo habían estado insistiendo los últimos treinta y dos años, o si éramos prodemocráticos como se atrevía a aseverar 
por escrito el nuevo Alto Mando de la institución" (p. 248). En un contexto donde, según el diagnóstico de las fuerzas armadas, la insurgencia estaba "reducida a una molestia" 25 y las acusaciones de violación a los derechos humanos al ejército eran cada vez más significativas, permanecer dentro del "conservatismo extremo radical", como lo definía Gramajo, no tenía razón de ser. El objetivo era autonomizar doctrinariamente al ejército, "liberarlo" de las ideologías, hacerlo más pragmático para adecuarlo al contexto de transición. En palabras de Gramajo, se buscaba un ejército "más pragmático en función de previsor del futuro, y en anticipada acción para equipararse a los tiempos y a las necesidades" ${ }^{26}$ Se buscaba la cohesión de la institución detrás del "interés militar" y dejar de lado las "presiones ideológicas". "Hay que dejar que los políticos luchen en sus batallas políticas; hay que dejar que los grupos económicos peleen sus propias batallas económicas" (directiva 3 -"L"-M-RAJAE. Citado en Gramajo, 1995, pp. 247-248).

Este objetivo planteado por los militares estratégicos se encontraba estrechamente anudado a la reflexión que venía llevando adelante el ejército respecto a su relación con el poder económico. Desde los años setenta del siglo xx había empezado a circular entre algunos oficiales de alto rango la idea de que la oligarquía económica explotaba al ejército. Los oficiales estratégicos asumieron esa perspectiva, rechazaban el supuesto papel histórico de subordinación a los grupos económicos dominantes e intentaban autonomizar al ejército de los intereses de esos grupos. En entrevista con Schirmer (1991b), Gramajo exclamó: "iya no somos los redentores de los latifundistas de la derecha... No tenemos contubernios, sino que somos profesionales!” (p. 13), y agregó:

Esta generación de oficiales militares es más profesional; o tal vez no tan profesional como están cansados de ser el peón de los políticos y hombres de negocios. Tal vez [creamos] nuestro esquema de profesionalización porque tomamos en cuenta la realidad de que nos habían usado y luego desechado. Estábamos acostumbrados por ellos y nadie nos dio las gracias; nos utilizaron

25 "La política como continuación de la guerra: general Gramajo", Boletín de la Agencia Centroamericana de Noticias ACEN-SIAG, núm. 64, 8 de julio de 1986. Colección RT, signatura 757. Archivo histórico cIRmA, Antigua, Guatemala. En su libro La estrategia fallida. El ocaso de la guerra popular prolongada, el militar retirado Víctor Manuel Ventura Arellano (2015) también sostiene que antes de la asunción de Cerezo la guerrilla constituía una "molestia", no una amenaza.

${ }^{26}$ Discurso del ministro de Defensa, general Héctor Gramajo Morales, 30 de junio de 1987, p. 5. Fondo ICA núm. 1484. Archivo histórico cIRMA, Antigua, Guatemala. 
y luego nos echaron la culpa de todo lo malo en Guatemala. Se trata de una nueva generación de soldados (p. 13).

Esta interpretación de la relación ejército-burguesía nacional niega el momento de modernización política y técnica en la que se vio inmerso el ejército a partir de 1954 y que lo llevó a asumir en 1963, mediante un golpe de Estado, el gobierno nacional en tanto institución. Ese proceso, como señala Torres-Rivas (1998, p. 39), condujo al ejército a transitar desde lo pretoriano a lo bonapartista, colocándose por encima de los intereses partidarios o privados, en tanto guardián de la nación, inaugurando una nueva modalidad de relación entre el ejército y la sociedad.

Gramajo hacía énfasis en todas sus intervenciones en la diferencia entre un soldado y un guerrero: "Cualquiera puede ser un guerrero -aprender a usar un arma, cortar el hígado y matar a todos. Esto es un esfuerzo desperdiciado. Un soldado usa su arma conscientemente, inteligentemente, y sólo en interés del país, no por intereses personales o de un grupo económico [...] Un guerrero representa la fuerza bruta; un soldado representa la fuerza mínima" (Schirmer, 1991b, p. 11). ${ }^{27}$

Para los estratégicos, se trataba de dejar de ser un "guerrero" para pasar a ser un "soldado" y para ello la formación de los oficiales era clave.

\section{Un nuevo rol político para las fuerzas armadas}

En el marco de los procesos de transición y de la teoría de las relaciones cívico-militares, la idea de "profesionalización" de las fuerzas armadas se utilizó para referir e impulsar la "despolitización" de la institución. Esta idea supone la posibilidad de cierta neutralidad y apoliticidad de las instituciones armadas. Sin embargo, la historia de las fuerzas armadas demuestra que la "profesionalización" no implica necesariamente alejamiento de lo político. Por un lado, y a modo de ejemplo, como señaló Alain Rouquié (1984), las fuerzas armadas latinoamericanas, el proceso de profesionalización de fines

${ }^{27}$ Véase, asimismo, Alejandro Gramajo, exministro de la Defensa. Mario Roberto Morales, entrevista. "La Guatemala de la posguerra. Una serie de entrevistas destinadas a visualizar nuestro futuro más inmediato” Revista Crónica, 6 de mayo de 1994, p. 24. Colección CHS, C8, núm. 13. Archivo histórico cirma, Antigua, Guatemala. 
del siglo xIx dio lugar al proceso inverso, al "intervencionismo militar" que "significó el fin de la hegemonía de los civiles en casi todos los países de la región" (p. 86). ${ }^{28}$ Por otro lado, este ejemplo indica, más que un proceso de politización de las fuerzas armadas, una prueba de ausencia de neutralidad partidaria, es decir, una injerencia en el sistema político, pero no una politización, porque ella ya existe de forma inevitable (Laleff Ilieff, 2011, p. 6). Las diversas críticas a la teoría de las relaciones cívico-militares han dado cuenta que la separación entre "lo político" y "lo militar", supuesto en el que se apoya esta perspectiva, es una separación un tanto equívoca. Oculta que las fuerzas militares son eminentemente políticas dado que su función reside en la protección de un entramado de relaciones de poder que se configura históricamente y que expresan vínculos de dominación (Laleff Ilieff, 2011, p. 6). Con ello queremos decir que la "profesionalización" que encaran los militares en Guatemala a fines del siglo xx, más que "despolitizar" a las fuerzas, intentará transformar a la institución para asumir un nuevo rol político. Todo instrumento armado organizado del Estado debe ser necesariamente político para defender el orden que le da vida. Y este es el objetivo de la corriente estratégica militar: reformular el rol (político) de las fuerzas armadas a tono con el proceso de reorganización del orden político en el país.

La DEN entendía al "poder militar" como un poder entre otros: económico, político, social. En su nuevo sentido de misión, el ejército no aparece subordinado al poder político, sino equiparado como un poder más. La alianza entre el gobierno de Cerezo y el alto mando militar era una muestra de ello. Esta interpretación del factor o "poder militar" realza la autonomía del ejército. La integración no implica subordinación, sino autonomía en la integración para actuar conjuntamente.

Ahora bien, el rol del "poder militar" frente al resto de los "poderes" en la etapa de transición es superior, está por encima de los otros poderes y

${ }^{28}$ La "profesionalización", concepto ambiguo, se usó en reiteradas ocasiones para describir procesos de cambio en las fuerzas armadas. Así, por ejemplo, a fines del siglo xIx se utilizó para caracterizar el proceso de conformación de las fuerzas armadas como institución nacional que hizo del oficio militar una profesión permanente, remunerada, que requiere estudios y preparación física e intelectual sujeta a normas burocráticas codificadas (Rouquié, 1984, p. 85). En el contexto de las transiciones al régimen democrático, la idea de "profesionalización" se asoció, en América Latina, con la idea de "despolitización" y autonomía castrense. En otros países occidentales, como señala Sabina Frederic (2013), la idea de "profesionalización" se utilizó para referir al proceso de cambio derivado de la eliminación del reclutamiento obligatorio de soldados en el marco del fin de la guerra fría. 
sus relaciones. El ejército mantiene una función trascendental, definida en la DEN, como "cuidar la democracia", las instituciones democráticas, garantizando la estabilidad. Según el general Manuel Antonio Callejas y Callejas, jefe del Estado Mayor de la Defensa Nacional: "la responsabilidad que nos asigna la carta magna tiene un significado trascendental y un profundo contenido". ${ }^{29}$ La Constitución de 1985 establece como funciones del ejército: "mantener la independencia, la soberanía y el honor de Guatemala, la integridad del territorio, la paz y la seguridad interior y exterior" (artículo 244). En el transcurso del periodo que se abre con la implantación de la democracia representativa, ello implicaba constituirse en el garante de la implantación de la democracia institucional, del proceso de transición institucional, a través de garantizar la tan mentada estabilidad.

En la tesis de ascenso, Análisis de los planes estratégicos del ejército y sus resultados, el autor comenta que del plan de campaña "Consolidación nacional 86" surgía como misión de las fuerzas armadas: "proporcionar las garantías de seguridad y paz, para que pudiera desenvolverse mejor el Presidente de la República como representante del pueblo de Guatemala, también para un mejor desenvolvimiento político, social y económico". ${ }^{30}$

La estabilidad, desde el punto de vista militar, implicaba asegurar el orden público, la "seguridad". Esta seguía siendo prerrogativa militar. En la tesis Organización profesional del ejército de Guatemala como fuerza armada. Un reto fututo al alto mando del ejército, de agosto de 1986, el autor recomienda:

[...] explotar la misión que ordena al ejército mantener la seguridad interior para que se autorice que todas las entidades, medios, mecanismos y fuerzas de seguridad se reorganicen bajo el mando y control del Ministerio de Defensa Nacional con un ente similar al del Estado Mayor del Ejército mientras se alcanza y se fortalece la Educación y conciencia del pueblo en este camino

${ }^{29}$ Expresión del general de Brigada, Manuel Antonio Callejas y Callejas, entonces jefe del Estado Mayor de la Defensa Nacional, en el foro nacional 27 Años de Lucha por la Libertad. Colección ICA núm. 1485. Archivo histórico CIRMA, Antigua, Guatemala.

${ }^{30} \mathrm{I}-86-\mathrm{X}-89$. Análisis de los planes estratégicos del ejército y sus resultados. Tesis de ascenso, julio de 1989. Guatemala: Centro de Estudios Militares. Biblioteca del Estado Mayor de la Defensa Nacional, ciudad de Guatemala. Consultado en noviembre de 2016. 
hacia la cimentación de la democracia. Posteriormente, al lograr este objetivo, el control del Ejército sobre los organismos de seguridad se iría diluyendo. ${ }^{31}$

En el lenguaje de la TEN, el ejército se encarga de la estabilidad, que implicaba controlar, enfrentar y/o eliminar a los "oponentes" del Estado en el marco de la ley. De tal forma, las fuerzas armadas se erigen en "protectoras de la democracia", pero ya no desde el control directo del gobierno, sino desde el cuartel.

\section{PALABRAS FINALES}

En términos generales, la DEN formulada por los militares estratégicos es un resultado del contexto democratizador de las instituciones políticas de los años ochenta en América Latina y del agotamiento de los postulados de la guerra fría. A nivel institucional, ese proceso adquiere su forma específica: la DEN no puede entenderse si no es a partir del proceso de reformulación de los supuestos básicos en los que se apoyaba el ejército desde 1954 plasmados en el PNSD y de la apropiación y reformulación, por parte de los militares estratégicos, de una serie de debates desatados en ese contexto: los debates en torno a la gobernabilidad, el rol militar en democracia, las teorías de las relaciones cívico-militares, las "nuevas amenazas". Este proceso se enmarcó en las disputas que los estratégicos llevaron adelante frente a los militares más "conservadores" respecto del rol de las fuerzas armadas en la sociedad, del manejo de la guerra y de las características que debía asumir la propia institución militar en la transición.

A partir de las ideas de "estabilidad-bienestar", integralidad, oponentes y fundamentalismo militar que analizamos en este trabajo surge la propuesta más importante de la DEN, la cual implica un nuevo rol político para el ejército en la sociedad: proteger la democracia desde el cuartel. Una democracia adaptada a las necesidades del proyecto estabilizador. El sentido de democracia que los militares impulsan anula la oposición "autoritarismo-democra-

${ }^{31}$ I-52-X-86. Organización profesional del ejército de Guatemala como fuerza armada. Un reto fututo al alto mando del ejército. Tesis de ascenso, agosto de 1986, p. 47. Guatemala: Centro de Estudios Militares. Biblioteca del Estado Mayor de la Defensa Nacional, ciudad de Guatemala. Consultado en noviembre de 2016. 
cia" planteado en las teorías de la transición y habilita la integración entre la contrainsurgencia y la institucionalidad democrática. Indudablemente, una democracia restringida a una serie de procedimientos institucionales como los electorales, que permite la reorganización del orden político sin modificaciones sustanciales al orden social. Esas fueron las bases ideológicas que dieron forma a la transición en Guatemala y que permiten explicar la posterior reconfiguración de la sociedad.

\section{LISTA DE REFERENCIAS}

Aguilera Peralta, G. (1994). Seguridad, función militar y democracia. Guatemala: Flacso.

Aguilera Peralta, G. (2008). Las amenazas irregulares en la agenda de seguridad de Centroamérica. En J. R. Perales (ed.), Reforma de las fuerzas armadas en América Latina y el impacto de las amenazas irregulares (pp. 5-13). Washington, D. C.: Woodrow Wilson International Center for Scholars Latin American Program.

Bustamante, F. (1986). Los paradigmas en el estudio del militarismo en América Latina. Santiago de Chile: Flacso (Documentos de Trabajo).

Camou, A. (2010). El discurso sobre la crisis de gobernabilidad de las democracias capitalistas avanzadas. Una revisión del informe de la "comisión trilateral" (19752010). Question, 1(27). Recuperado de https://perio.unlp.edu.ar/ojs/index.php/ question/article/view/990

Canelo, P. (2008). El proceso en su laberinto. La interna militar de Videla a Bignone. Buenos Aires: Prometeo.

CEG (1995). Guatemala: entre el dolor y la esperanza. Valencia: Universitat de València.

Devés Valdés, E. (2003). El pensamiento latinoamericano en el siglo XX. T. I. Desde la CEPAL al neoliberalismo (1950-1990). Buenos Aires: Biblos.

Figueroa Ibarra, C. (1999). Los que siempre estarán en ninguna parte. La desaparición forzada en Guatemala. México: Grupo de Apoyo Mutuo/Centro Internacional para la Investigación en Derechos Humanos/Instituto de Ciencias Sociales y Humanidades.

Figueroa Ibarra, C. et al. (2013). Guatemala: historia reciente 1954-1996. Tt. I y II. Guatemala: Flacso.

Frederic, S. (2013). Las trampas del pasado: las fuerzas armadas y su integración al Estado democrático en Argentina. Buenos Aires: Fondo de Cultura Económica.

Gramajo, H. A. (1989). Tesis de Estabilidad Nacional. Guatemala: Editorial del Ejército. 
Gramajo, H. A. (1995). De la guerra... a la guerra. La difícil transición política en Guatemala. Guatemala: Fondo de Cultura Editorial.

Huntington, S. (1995). El soldado y el Estado. Teoría y política de las relaciones cívico-militares. Buenos Aires: Grupo Editor Latinoamericano.

Janowitz, M. (1967). El soldado profesional. Retrato político y social. Buenos Aires: Editorial Bibliográfica Argentina.

Kruijt, D. y Van Meurs, R. (2000). El guerrillero y el general: Rodrigo Asturias y Julio Balconi sobre la guerra y la paz en Guatemala. Guatemala: FLAcso.

Laleff Ilieff, R. J. (2011). Gramsci y la cuestión militar argentina. Apuntes críticos para pensar la violencia estatal.e-l@tina. Revista Electrónica de Estudios Latinoamericanos, 10(37), 3-17.

López, E. (1985). Doctrinas militares en Argentina: 1932-1980. En C. Moneta, E. López y A. Romero, La reforma militar (pp. 103-143). Buenos Aires: Legasa.

López, E. (1987). Seguridad nacional y sedición militar. Buenos Aires: Legasa.

Poitevin, R. (2000). Modernizar para militarizar: el gobierno paradigmático de Arana Osorio. Anales de la Academia de Geografía e Historia de Guatemala, 75, 229-258.

Rosada Granados, H. (2011). Soldados en el poder: proyecto militar en Guatemala (19441990). Guatemala.

Rostica, J. (2018). La transnacionalización de ideas: la escuela contrasubversiva de Argentina a Guatemala. Diálogos. Revista Electrónica de Historia, 19(2), 149-176. DOI: http://dx.doi.org/10.15517/DRE.V19I2.31140

Rouquié, A. (1984). El Estado militar en América Latina. Buenos Aires: Emecé Editores. Sala, L. (2018a). En búsqueda de una doctrina contrasubversiva propia. Las tesis de ascenso de los oficiales guatemaltecos, 1975-1985. Ponencia presentada en Congreso LASA2018, Latin American Studies Association, Barcelona, España, del 23 al 26 de mayo de 2018.

Sala, L. (2018b). Los militares estratégicos y la reformulación del pensamiento militar. Guatemala 1978-1986. Latinoamérica. Revista de Estudios Latinoamericanos, 67, 203-238. DoI: http://dx.doi.org/10.22201/cialc.24486914e.2018.67.57034

Schirmer, J. (1991a). Guatemala: los militares y la Tesis de Estabilidad Nacional. En D. Kruijt y E. Torres-Rivas (coords.), América Latina: militares y sociedad (t. I, pp. 183-219). San José: Flacso.

Schirmer, J. (1991b). The guatemalan military project: An interview with gen. Héctor Gramajo. Harvard International Review, 13(3), 10-13.

Schirmer, J. (1996). La otra cara de la dimensión internacional: el saqueo del discurso democrático por parte de los militares guatemaltecos. En E. Jelin y E. Hershberg 
(coords.), Construir la democracia: derechos humanos, ciudadanía y sociedad en América Latina (pp. 97-110). Caracas: Nueva Sociedad.

Schirmer, J. (1999). Intimidades del proyecto político de los militares en Guatemala. Guatemala: Flacso.

Soprano, G. (2013). La profesión militar en los estudios sobre fuerzas armadas y sociedad. Lecturas, interpretaciones y usos desde la Argentina actual. Cuadernos de Marte, 4(5), 63-97. Recuperado de https://publicaciones.sociales.uba.ar/index. php/cuadernosdemarte/article/view/57

Torres-Rivas, E. (1991). Centroamérica: la transición autoritaria hacia la democracia. Revista de Estudios Políticos. Nueva época, 74, 431-448. Recuperado de https://dialnet.unirioja.es/servlet/articulo?codigo $=27125$

Torres-Rivas, E. (1993). América Latina. Gobernabilidad y democracia en sociedades en crisis. Nueva sociedad, 128. Recuperado de https://nuso.org/media/articles/ downloads/2291_1.pdf

Torres-Rivas, E. (1998). Construyendo la paz y la democracia. El fin del poder contrainsurgente en Guatemala. En E. Torres-Rivas y G. Aguilera Peralta, Del autoritarismo a la paz (pp. 7-111). Guatemala: Flacso.

Torres-Rivas, E. (2007). ¿Qué democracias emergen de una guerra civil? En W. Ansaldi, La democracia en América Latina, un barco a la deriva (pp. 491-527). Buenos Aires: Fondo de Cultura Económica.

Ventura Arellano, V. M. (2015). La estrategia fallida. El ocaso de "una guerra popular prolongda”. Guatemala, 1979-2000. Guatemala: Edición a cargo del autor.

\section{OTRAS FUENTES}

\section{Archivos}

AHGC Archivo Histórico General de Centroamérica, ciudad de Guatemala.

CIRmA Archivo Histórico. Centro de Investigaciones Regionales de Mesoamérica, Antigua, Guatemala.

Biblioteca del Estado Mayor de la Defensa Nacional, ciudad de Guatemala. 